\title{
Wireless Charging for Autonomous under Water Vehicles
}

\author{
Rahul Karale $^{1} \mid$ Kadagala Venkata Srinivas ${ }^{2}$ | I. E. S.Naidu ${ }^{3}$ \\ ${ }^{1}$ EEE Department, Gitam Institute of Technology, Visakhapatnam, India. \\ ${ }^{2}$ TPD Department, NSTL (DRDO) , MOD, Visakhapatnam, India. \\ ${ }^{3}$ EEE Department, Gitam Institute of Technology, Visakhapatnam, India.
}

\section{To Cite this Article}

Rahul Karale, Kadagala Venkata Srinivas and I. E. S.Naidu, "Wireless Charging for Autonomous under Water Vehicles", International Journal for Modern Trends in Science and Technology, Vol. 06, Issue 06, June 2020, pp.:142-150; https://doi.org/10.46501/IJMTST060629

\section{Article Info}

Received on 18-May-2020, Revised on 02-June-2020, Accepted on 09-June-2020, Published on 22-June-2020.

\section{ABSTRACT}

In Modern days robotics have taken up the space in the form of Autonomous Underwater Vehicles (AUVs) throughout the marine environment. As the robustness, complexity, efficiency and reliability, has increased simultaneously the ability of AUVs to perform complex missions too. The tasks that once required a fleet of ships, several months to complete, and numerous divers are now being performed by AUVs. So many technology advancements have been made in the field of AUVs still the time to last for longer duration remains a limiting factor. Removal of mines, deep search and in disaster situations it proves to be advantage to environment. Most of the AUVs are using the energy stored in the form of battery. But to deploy the AUV for a mission requires charging it above water which is time intensive. Depending on weather conditions, sea state, and is often dangerous for crew member as well as AUV. While deployment and recovery will remain critical, there exists a need to find a safer and faster recharging method that saves time \& does not require recovery of AUVs. This paper proposes the power transfer and rapid charging techniques of AUVs reliability to charge a single battery pack faster. Power is transferred through the uses of inductive coils. It is then transferred to a step down buck converter with feedback controller under the varying load voltage. The system is capable of transferring up to $500 \mathrm{~W}$ of instantaneous power to a single battery pack. Further It is electrically isolated from the power source and can be easily integrated into an AUV for testing in future.

KEYWORDS: energy, power transfer, rapid charging

Copyright (C) 2014-2020 International Journal for Modern Trends in Science and Technology

DOI: https://doi.org/10.46501/IJMTST060629

\section{INTRODUCTION}

The work presented here was done in collaboration with the Naval Science and Technological Laboratory (DRDO), Visakhapatnam. Applications of Power electronics are required for this type of application to provide fast, "smart" charging of the battery cell without been damaged. This type of Charging requires a well-regulated DC charging current. For this a step down buck converter with a feedback control was designed, built, and demonstrated to supply a $10 \mathrm{~A}$ DC current to a battery cell for rapid charging. Because the system is intended to be built into a volume-restricted AUV, size and weight were also important designed parameters.

Additional research and work are in progress for development of power storage cell system and 
wireless power transfer coils. Now being able recharge the AUV under water or man the surface vessel responsible for providing charging power. This has proved beneficial for both commercial and Defence application.

A successful demonstration of AUV recharging has the potential to greatly decrease AUV deployment and maintenance costs as well as increase mission availability. The ultimate aim of this research is to increase mission duration long deployment/ capture, data download, and recharge cycles. This AUV outfitted with the charging system envisioned will perform for longer duration as compared to AUVs currently in use.

\section{BACKGROUND}

The charging system being developed could be placed in any remotely-piloted vehicle, but the focus of this paper is on AUVs and AUV applications. AUVs are in our environment approximately since 60 years. Since inception, they have transformed toys to autonomous platforms outfitted with new technology and advanced sensors. As their complexity increases, so does the application. Nowadays, AUVs are used in commercial and Defence applications. The tasks AUVs are performing is growing day by day.

\section{AUVS IN THE MARINEENVIRONMENT}

In today's world oil and gas industry are the largest employer of AUVs. These industry uses AUVs to survey the ocean floor to help find new well sites. They cost less, provide better data, and are capable of covering larger areas than surface vessels conducting the same work. Over time, these industries have expanded their use for surveying platform to perform other tasks like geohazard/clearance surveys; rig site surveys; acoustic inspection of pipelines and sub-sea installations; pipeline route surveys; and construction site surveys [2].

The telecommunication industry performs surveying and cable laying with AUVs while the mining industry is mostly conducting more standard AUV surveying missions. AUVs are also used quite heavily by researchers and scientist, with oceanographic surveying being the principle mission. A variety of onboard sensors, however, also support the work of marine biologist and researchers.

The Indian Navy is also very interested in developing an "fleet" of AUVs to perform a variety of warfare mission:-
1. Intelligence, Surveillance, and

Reconnaissance(ISR)

2. Mine Countermeasures(MCM)

3. Anti-Submarine Warfare(ASW)

4. Inspection /Identification

5. Oceanography

6. Communication / Navigation NetworkNode

7. PayloadDelivery

But a single AUV cannot perform all tasks. However, a fleet of AUVs with different payloads might be able to accomplish all tasks.

\section{GENERAL ARRANGEMENT OF A AUV}

A torpedo-shaped AUV is assumed, the general arrangement of such an AUV is illustrated in Figure 1. The forward end of the vessel is dominated by structure and electronic equipment. The electronic equipment includes both processing components such as the main computer and all sensors. Navigation equipment is contained in this portion of the AUV. This section can also be referred to as the payload.

Aft of the payload is the power source. The aft section of the AUV is reserved for propulsion and control surfaces. Propulsion is typically provided through a single shaft, single propeller design. Ducting is also often used to increase propulsive efficiency.

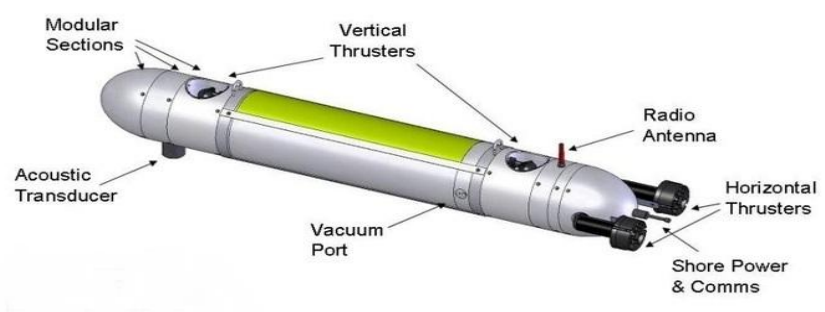

Figure 1: General Arrangement of a Notional Torpedo-Shaped AUV

\section{METHOD OF DEPLOYMENT}

Very less AUVs are there that can be handled by a single person. Usually a team of people are required to accomplish a specific task, such as system deployment from a surface vessel. Because of support equipment is required, deployment of the AUV is very costly. It requires acceptable surface platform, the installation of support equipment, and finally on station time as the AUV 
must be recovered upon completion of its mission or when its battery drains off. Launching and recovery is very costly in terms of system failures. The AUV is vulnerable to damage when it is in the process of being deployed or recovered.

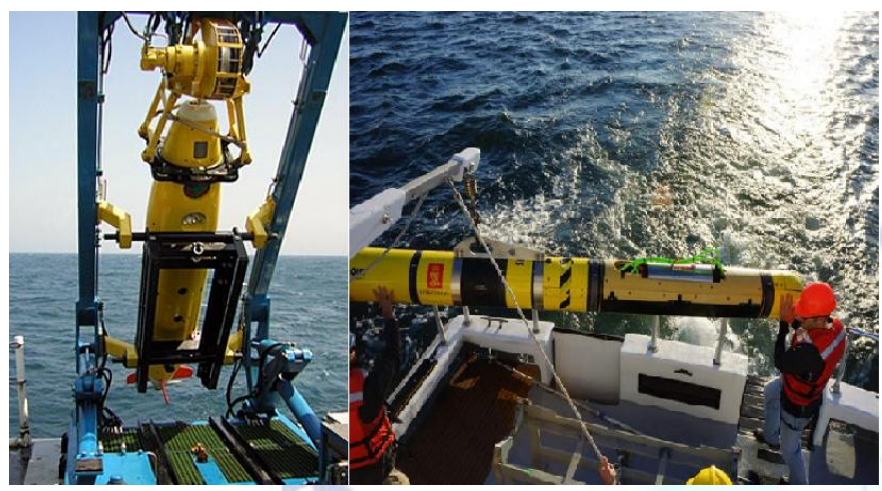

Figure 2: REMUS 600 Launch \& Recovery System (LARS) [6]

Charging is typically accomplished by removing the AUV from the water and plugging its power cell into an appropriate power supply. The charging process is slow requires time to again mount the battery in case and check everything before going for a mission.

\section{CHARGING CHALLENGES \&BENEFITS:-}

Since the launching and recovery is very costly and dangerous for system damage and failure, it is desirable to minimize the frequency of launch and recovery. Another way to minimize the frequency of launch and recovery is to charge the AUV between missions in the marine environment. The benefit is AUV will only be launched and recovered once per mission and Secondly, to remain on station to monitor the AUV evolves; there may, in fact, no longer be a need at all to remain on station to monitor AUV.

Active charging can also take place underwater. A surface vessel outfitted with the proper charging equipment could mate with the AUV for a short period of time and rapidly charge the AUV's. Inactive charging could also be accomplished with some sort of fixed or floating charging station. There are two power transfer methods available for charging an AUV power cell in the water: conduction and induction.

Inductive charge transfer is the best method of power transfer. Induction relies totally on coupling of magnetic fields and a secondary coil (or coils) couple to the magnetic field, developing a voltage potential proportionally to the amount of magnetic flux experienced in accordance with Maxwell's equations and Faraday's Law.

Induction is safe in the marine environment, because there are no exposed electrical connections and no direct transfer of charge. As a result, there is no potential for shorting or galvanic corrosion. Power is transferred through magnetic fields only.

\section{PREVIOUS WORK WITH AUV CHARGING}

A lot of work of work has been done by a number of different research labs and commercial companies to develop underwater AUV charging docks. Methods vary, and success has been incrementally improved over the years. A review of the most recent docking stations and methods is provided in the following sections.

\section{AOSN DOCK}

One of the first attempts to dock and recharge an AUV was the Autonomous Ocean Sampling Network (AOSN) docking system. Designed specifically for the MIT Odyssey II AUV, the AOCN dock provides a recharging and data transfer capability.

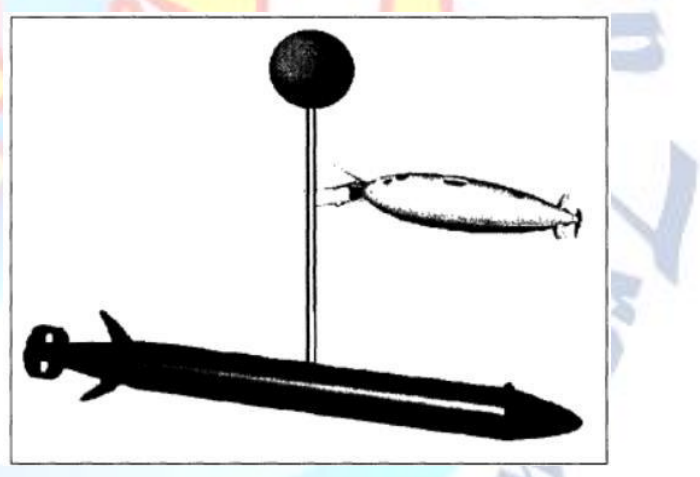

Figure 3: AOSN Docking System for the MIT Odyssey II AUV

\section{MIT AUV RECHARGINGSYSTEM}

A variation of the AOSN docking system was designed and lab tested at MIT Sea Grant by L.A. Gish in 2004 [1]. Again induction was pursued, but with a slight variation. Rather than align the induction coils with the mechanically unreliable winch system featured in the AOSN dock, the tether itself could be used for power transfer, 


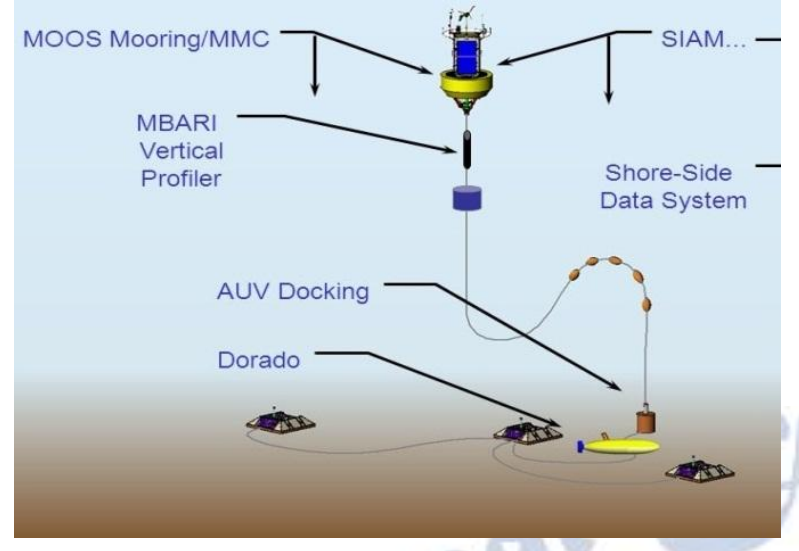

Figure 4: AUV Recharging System using LCWT [9]

\section{REMUS 600Dock}

Hydroid, a commercial company owned by Kongsberg Maritime, has been producing the popular REMUS series of AUVs for several year. WHOI fielded a prototype docking station for the REMUS 100 AUV in 2001 [3]. This prototype docking station sought to remove the AUV from the dynamic nature of the ocean environment by providing a cylindrical housing enclosure.

The AUV was driven into a cylindrical tube and mechanically retained prior to the initiation of power transfer or data download. A graphic of the prototype is provided in Figure 5.

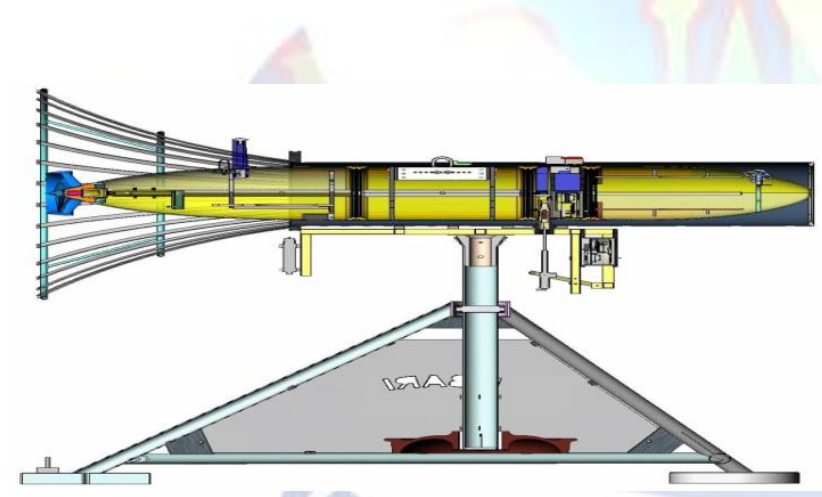

Figure 5: REMUS 100 Docking Stations developed by WHOI. Fielded 2001 [3]

\section{BLUEFIN 21DOCK}

Hydroid is not alone in its efforts to find a docking station for its AUVs. Bluefin Robotics, another manufacturer of world-class AUVs, has also developed proprietary docking stations for its much larger 21" diameter Bluefin-21 AUVs. The concept of operation, however, is varied little from those developed by WHOI and Hydroid. A docking cone is used to guide the AUV into a cylindrical retaining tube in which power and data transfer are accomplished [4]. The docking station was developed in collaboration with Battelle[5] and is shown in Figure6

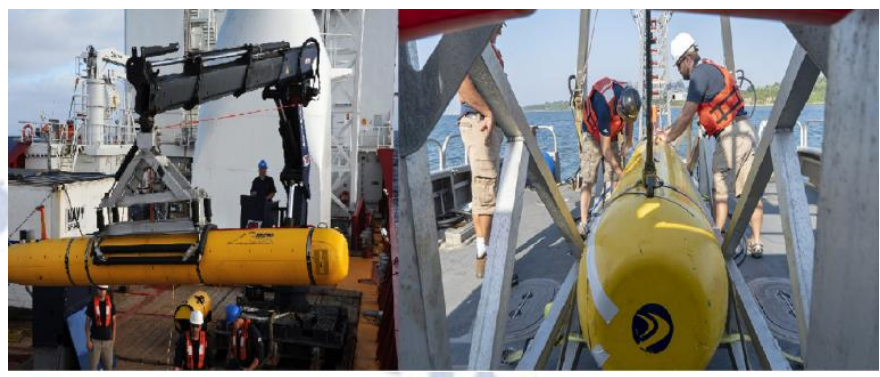

Figure 6: Battelle-developed Docking Station for Bluefin 21 AUV

The Battelle solution is unique in that the docks can be stacked and joined together to form docking modules permitting the docking of any number of AUVs at a given time. Separation of cells is performed using acoustic beckon signal at the entrance to each dock. Additionally the dock and AUV can be deployed together. The entire system is lowered to the seafloor. The AUV then drives out of the dock and returns when its mission is complete or power is needed.

\section{F. DOCKING/CHARGING STATIONISSUES:-}

The charging station does not come without its challenges. Firstly, bio-fouling of sensors and components is a real concern, Optical sensors and induction coils do not work well when covered in marine growth. Secondly, the docks currently are designed to carry a single recharging battery pack. Once the AUV is recharged once or twice, the charging station much be brought to the surface and recharged itself. Finally, the AUVs are limited in navigational intelligence and usually the AUV fails to enter the dock. As algorithms and artificial intelligence of these systems increases, their reliability will also increase.

\section{METHODOLOGY}

\section{PROPOSED SYSTEMOVERVIEW}

The charging system proposed comprised of three separate components. First power source which includes both the power supply and the inductive coils.

The power converter is the second component. The final component is the battery pack. A system overview is shown in Figure 7. 


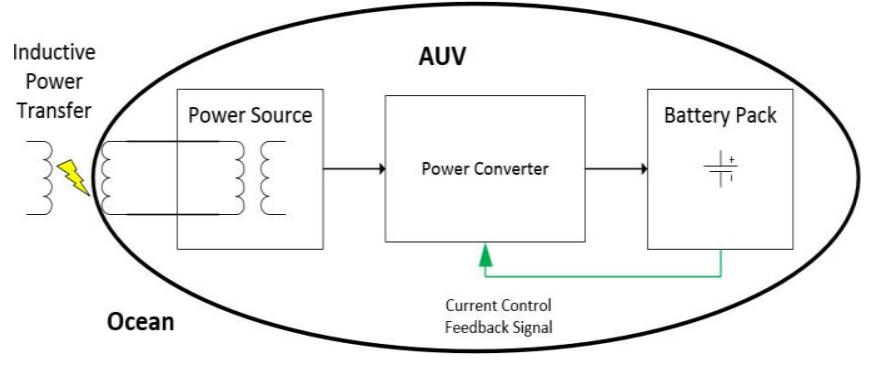

Figure 7: Power System Overview

The aim of this paper is to design and to build the power converter block. Focusing on the power converter required successfully decoupling it from the rest of the system.

\section{BATTERY PACK SPECIFICATIONS}

The AUV battery pack used for this project was a known design constraint. Each pack will consist of 12 A123 ANR26650M1-B Nanophosphate ${ }^{\circledR}$ High Power Lithium Ion (Li-Ion) Cells. These cells are arranged in series with a nominal cell voltage of $3.3 \mathrm{~V}$ [7].but it can vary from $3.7 \mathrm{~V}$ to $3.3 \mathrm{~V}$.the Output voltage is expected to be between $39.6 \mathrm{~V}$ and $44.4 \mathrm{~V}$.

These cells are capable of fast-charging at 10A. Charging AUVs in the water presents unique challenges for the charging evolution. On dry land, charging can be completed over long periods of time and under calm conditions. At sea the AUV is to remain in the water during the charging evolution, charging as fast possible is desirable.

The desired output power of the system is calculated as follows:

Pout $=$ IoutVout,$=10 \mathrm{~A} * 44.4 \mathrm{~V}=440 \mathrm{~W}$

\section{POWER CONVERTERSPECIFICATIONS}

The specifications for the power source and battery pack permit the proper specification of the power converter. The high input voltage suggests the use of a non-isolated step-down (buck) converter. However, even if the input is not high voltage, low current, an appropriate input transformer can be selected to adjust the input voltage to an POWER

acceptable operating range, permitting the use of a buck converter.

A buck converter topology is not the only option that could have been chosen. Numerous switching mode power supply (SMPS) topologies exist that would have acceptable for the application described herein. We chose buck converter topology was for a few basic reasons: Efficiency, Flexibility, Simplicity of Design ,Reliability and
Constant Output Current. The need to regulate the output needed feedback control design.

Table 1: Buck Converter Requirements \& Specifications

\begin{tabular}{|c|c|}
\hline REQUIREMENT & SPECIFICATION \\
\hline Input Voltage Range & $60-75$ VAC \\
\hline Input Voltage Transient Lin & $\begin{array}{l}80 \mathrm{VAC} \text { for up to } \\
1 \mathrm{~ms}\end{array}$ \\
\hline $\begin{array}{l}\text { Output Power Range } \\
\text { (Resistive Load) }\end{array}$ & $500 \mathrm{~W}$ \\
\hline Output Voltage & 39.6-44.4VDC \\
\hline Output Current Transient & $\begin{array}{l}\text { Never }>14 \mathrm{~A} \\
12 \mathrm{~A}+\text { for }<0.5 \mathrm{~ms}\end{array}$ \\
\hline Output Voltage Ripple & $5 \mathrm{mV}$ or less \\
\hline Input Current Ripple & $100 \mathrm{~mA}$ \\
\hline Min Efficiency & Q4 \\
\hline Ambient Temp Range & $-20^{\circ} \mathrm{C}$ to $25^{\circ} \mathrm{C}$ \\
\hline
\end{tabular}

The step down buck converter was chosen because it offers both compactness and reliability.

\section{CONVERTER DESIGN}

The necessity to design a step down buck converter with feedback control was to Firstly charge a battery pack because of fact that Batteries are DC components that required DC current for charging and Secondly, the converter input voltage requirement was 60-75VDC.

\section{BUCK CONVERTER THEORY}

A buck converter is a DC-DC converter than takes a high voltage input and converts it to a lower voltage output through switching action. Real converters lose power in the form of heat in both switches as well as the inductor. Figure 8 shows a basic buck topology.

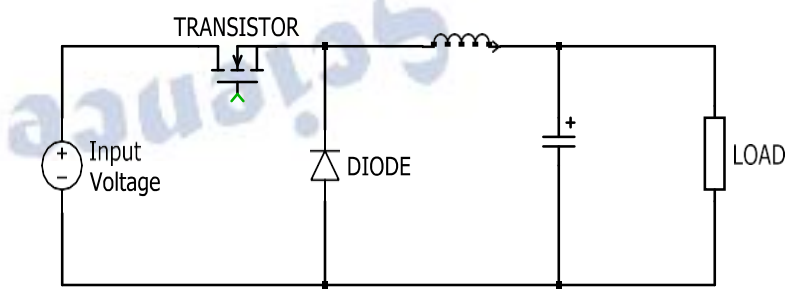

Figure 8: Basic Buck Converter Topology

The buck converter works by swapping conduction between two power switches. In Figure 9, the two switches are the power transistor and the diode. The power transfer process starts with the first 
switch: the power transistor. A control signal turns the transistor "on." It conducts and transfers the input voltage to the load through the inductor $\mathrm{L}$. The inductor builds up current and stores energy in its magnetic field during this stage. The control signal then turns the transistor "off" for the second part of the operational cycle. The input voltage is isolated from the load, but the current flowing in $\mathrm{L}$ cannot instantaneously change. Energy stored in the magnetic field of $\mathrm{L}$ continues to drive current to the load, inducing a negative voltage across the freewheeling diode. The diode turns "on" and permits current to be delivered to the load. L and C act as a second order filter to smooth the output waveform. The load experiences an averagevoltage proportional to the fraction of the transistor's per cycle "on" time. Depending on how long the transistor is on per cycle, more or less power is delivered. The ratio of the "on" time to total cycle time is called the duty cycle D. For a buck converter, the relationship between duty cycle $\mathrm{D}$ to input and output voltage is:

$V_{\text {out }}=D V_{\text {in }}$

A complete theoretical description of how a buck converter operates is provided in Principles of Power Electronics [8].

\section{POWER CONVERTER DESIGNOVERVIEW}

The simple buck converter is not sufficient for the AUV charging circuit, because of the fact actual input is not a DC power supply at all, but an AC waveform that must be transformed, rectified, and filtered to approximate DC. Additionally, input filtering and output filtering was required to ensure an acceptably smooth current waveform was delivered to the battery at all times. The actual designed converter topology is shown in Figure 9.

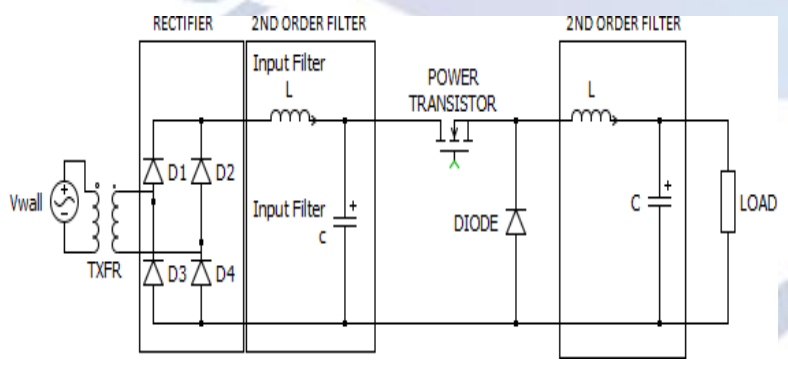

Figure 9: Buck Converter Topology for AUV Charging System

Using a transformer at the frontend of this converter permits a much higher level of flexibility with this design than might otherwise be present

\section{SWITCHING FREQUENCY SELECTION}

In general, higher switching frequencies are preferred for power converters as they permit the use of smaller (and usually cheaper) inductors and capacitors - both for filtering and power conversion [9]. Smaller passive components translate to smaller board and volume requirements and more compact designed. Compactness is ultimately the driver for using a higher switching frequency is this application. Volume onboard an AUV is valuable and limited. The recharging system cannot be allowed to monopoly vital volume needed for useful sensor payloads, like sonar and acoustic modems

\section{SWITCH SELECTION: POWERDIODE}

The diode was the first power electronics switch selected in the design process. From the requirements, the diode will need to be able to withstand a maximum input voltage of $80 \mathrm{~V}$ for $1 \mathrm{~ms}$. This requirement captures the need to protect the diode during transient load changes during which the voltage across the device can spike. The diode must also be able to withstand the maximum current it is likely to experience during regular operation. A calculation is required to determine the steady-state maximum diode current $<$ diode, $>$.

To find $<$ Idiode, $>$, first the maximum output current $I_{\text {out }}$, ax must be determined.

\section{SWITCH SELECTION: POWERTRANSISTOR}

The second power switch that needed to be characterized and selected was the actively controlled power transistor. For this application, an N-Channel MOSFET switch was chosen. Similar to the diode, the MOSFET needed to be rated to withstand the maximum input voltage transient of $80 \mathrm{~V}$ for $1 \mathrm{~ms}$ and to handle the maximum average MOSFET current $<I F E T$, $>$. It will also need to be as efficient as possible to prevent exceeding the desired $90 \%$ efficiency. The calculation for $<I F E T$, >assumes the worst case efficiency, lowest input voltage, and highest duty ratio

\section{INPUT FILTER PASSIVE COMPONENTSELECTION}

A $2^{\text {nd }}$ order LC low-pass filter is required for block high frequency components of the input power. The parallel LC tank depicted in Figure 10 forms the foundation of the input low-pass filter design. The additional impedance $\mathrm{Z3}$ is known as $\mathrm{Rd}-\mathrm{Cd}_{\mathrm{d}}$ 
parallel damping. Parallel damping was introduced into the

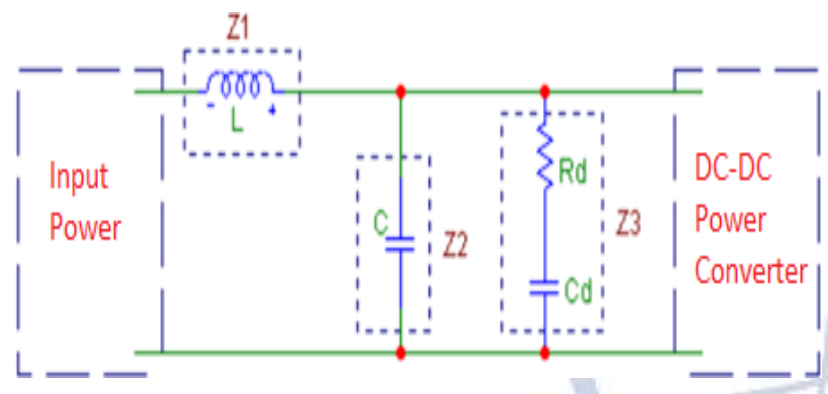

Figure 10: Input Filter to Buck Converter Switching Component

\section{CIRCUIT MODELING \& SIMULATION INMATLAB ${ }^{\circledR}$}

Performance validation of the complete charging circuit was conducted in MathsWorks MATLAB®. MATLAB $\triangle$ is a multi-paradigm numerical computing environment and proprietary programming language developed by MathWorks. A variety of other simulation software packages, such as Cadence's PSpice ${ }^{\circledR}$, plexims PLECS exist and could have been used, but personal knowledge

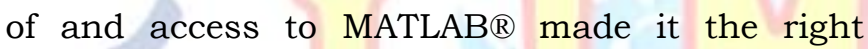
solution for this project. The goal of modeling was to build an accurate representation of the circuit that could later be used to assist in the printed circuit board (PCB) design effort.

\section{COMPLETE CHARGE CIRCUIT MODEL}

The full model of the charging circuit consists of seven distinct sections or segments (Figure 11). In the first circuit segment, AC power is delivered to the circuit from the test source and transformed to a lower voltage. The full bridge rectifier and smoothing capacitors converter AC to DC in the second segment. The input power is then filtered through the 2nd order input filter and passed to the power switches for DC-DC power conversion. The output 2 nd order filter then conditions the voltage and current waveforms in the 5 th segment for delivery to the battery pack.

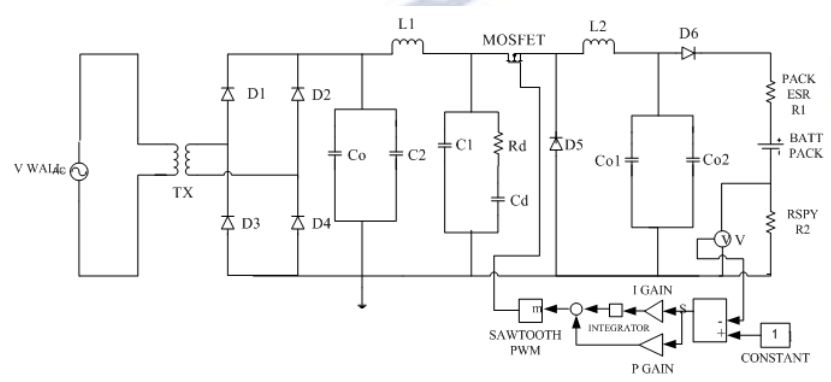

Figure 11: Full Circuit MATLAB® Model with Sections Highlighted
A diode was added at the input to the battery pack to prevent the battery voltage from attempting to reverse power the converter. It serves as a one-way valve, as shown in the battery pack section of Figure 31 . The sense and control circuit models appear in the block blocks. The sense resistor is accurately modeled as a resistor, while the voltage signal is approximated with the use of a voltmeter and feedback control blocks. The output of the feedback model drives the gate of the MOSFET, permitting simulation of the complete circuit. The next section will examine the voltage and current waveforms as they transit through the system to the battery pack.

\section{RESULTS}

\section{SIMULATION RESULTS \& SYSTEM WAVEFORMS}

Numerous simulation of the circuit model presented in Figure 11 were conduct during the design process. To validate the performance of the circuit, voltage and/or current waveforms were examined at the entry and exit of every stage of the system.

The first stage of the system is a 2.3:1 transformer followed by the full bridge rectifier with smooth capacitors. Because the transformer is $2.3: 1$, the 230VAC input is expect to be transformed to an approximately 52VAC waveform. The transformed waveform appears in the top of Figure 12

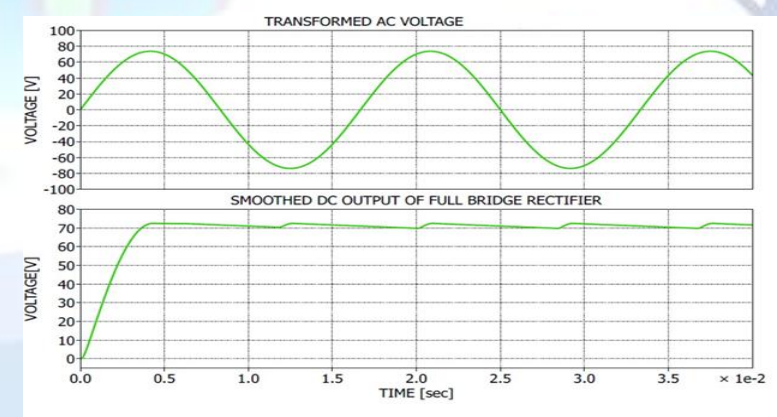

Figure 12: Transformer and Smoothed DC Output of Full Bridge Rectifier Voltage Waveforms

The transformed voltage is then rectified with the use of a full bridge rectifier. The expect peak output voltage is $52 \sqrt{2}$, or $73.5 \mathrm{VDC}$, minus double the forward voltage drop (Vf) of the diodes used in the full bridge rectifier. $\mathrm{Vf}$ is approximately $0.5 \mathrm{~V}$ for each diode, so the expected peak voltage should be around $72.5 \mathrm{VDC}$. This is clearly shown in the second waveform of Figure 13.

The addition of smoothing capacitors at the output of the full bridge rectifier permits a gradual 
decrease in peak voltage and holds up the voltage until the second half of the diode bridge commutes and rectifies the opposite swing of the input $\mathrm{AC}$ waveform. With the two waveforms of Figure 13 align in time, it is easy to see that peaks in the smoothed rectifier output coincide with positive and negative peaks in the input $\mathrm{AC}$ waveform. The input filter is therefore expected to complete smooth the input voltage and eliminate this problem in the final application.

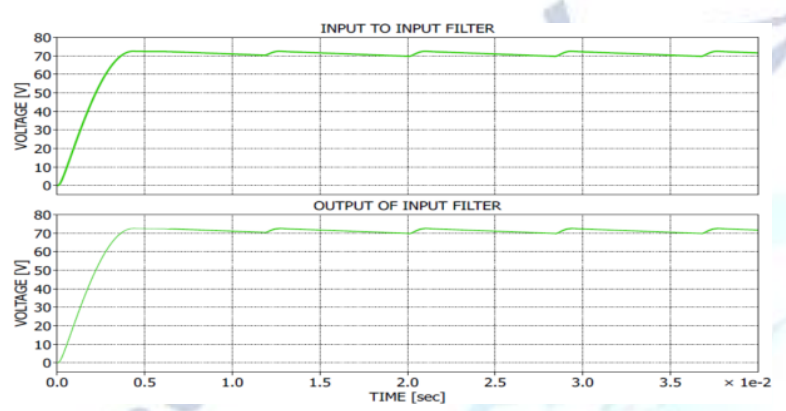

Figure 13: Input Filter Voltage Wave Forms

There is a high frequency component to this waveform that the filter removes, as shown in the bottom plot of Figure 14. The filter averages the voltage signal as well, resulting in a reduction of the peak voltage from approximately $70 \mathrm{~V}$ to $45 \mathrm{VDC}$. The $120 \mathrm{~Hz}$ ripple is still present, as expected, manifesting itself as a slight bump in the output voltage waveform. This voltage is delivered to the battery during the charging cycle

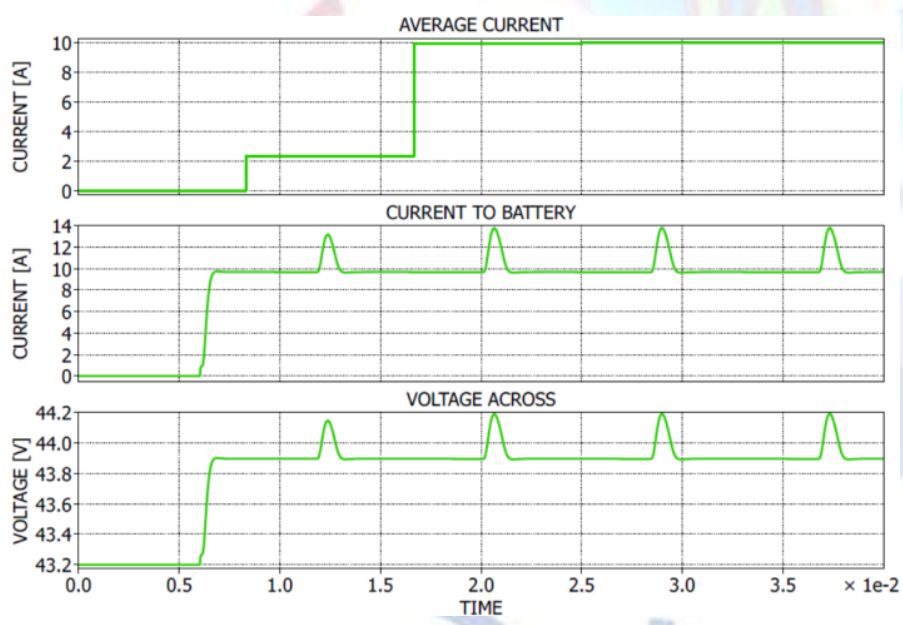

Figure 14: Battery Pack Current and Voltage Waveforms

Changing nothing else but the input frequency of the power source to $1 \mathrm{MHz}$, the battery current waveform becomes the waveform shown in Figure 14. The peaks in the current are completely eliminated, and the current never overshoots 10A, which is excellent for the reliability of the battery pack over extended use and cycling.

\section{DISCUSSION}

\section{RECOMMENDATIONS FOR FUTURE WORK}

The work presented in this paper presents a small proof-of-concept step towards the development of a successful wireless, underwater AUV recharging system. The area of future work deals with system integration work in NSTL (DRDO), VIZAG is ongoing to develop the battery pack and the inductive power transfer pieces of this engineering puzzle. Ultimately, the pieces need to work together to deliver energy to the AUV. Integration of these pieces is crucial to the success of the final product.

There is also an integration piece that deals with the packaging of the converter into an appropriate volume and area for the AUV. Some work needs to be done to determine what that volume and area will be. The converter is intended to be housed in the pressure chamber of the AUV. This will require some careful systems engineering to ensure the heat dissipated by the converter is properly managed and dissipated. At this point, it would also be smart to establish a final energy storage size requirement to determine the number of battery cells that will be required. $5.0-5.5 \mathrm{kWh}$ was the range most frequency discussed, but this is subject to change.

Finally, there is real potential for future work testing the impact of an induction system on both the AUV and its internal sensors and components as well as the operating environment. Finally this project is in need of an automatic tuning feature for the induction coils. Already, lab results have shown that ability to transfer power over distance is closely related to the quality factor $Q$ of the system and resonance. Both change slightly with distance and orientation of the coils in saltwater.

Developing an automatic tuning circuit which would be capable of zeroing in on the resonance peak of the system given its distance and orientation would greatly assist in the development of a truly efficient power transfer system.

\section{REFERENCES}

[1] L. A. Gish, "Design of an AUV Recharging System," 2004.

[2] G. Griffiths, Technology and Applications of Autonomous Underwater Vehicles. CRC Press,2002.

[3] R. Stokey, B. Allen, T. Austin, R. Goldsborough, N. Forrester, M. Purcell, and C. von Alt, "Enabling Technologies for REMUS Docking: An Integral Component of an Autonomous Ocean-Sampling Network," IEEE J. Ocean. Eng., vol. 26, no. 4, pp. 487-497, 2001. 
[4] R. S. Mcewen, B. W. Hobson, and J. G. Bellingham, "Docking Control System for a 21 " Diameter AUV."

[5] B. Geoghegan and R. Granger, "The Battelle-developed UUV Docking and Recharging Station : Meeting Oil and Gas clients ' needs," 2011. [Online]. Available: http://projects.battelle.org/ogupdates/2013Q2/docking.pdf. [Accessed: 09-Apr-2014].

[6] C. G. Rauch, M. J. Purcell, T. Austin, and G. J. Packard, "Ship of Opportunity Launch and Recovery System for REMUS 600 AUV's," Ocean. 2008, pp. 1-4,2008.

[7] A123 Systems Inc., "Nano phosphate ® High Power Lithium Ion Cell Nano phosphate ${ }^{\circledR}$ High Power Lithium Ion Cell," Waltham, MA, 2011.

[8] J. G. Kassakian, M. F. Schlecht, and G. C. Verghese, Principles of Power Electronics. Cambridge, MA: Prentice Hall, 1991. 